\title{
Research on the Influence Factors of the Policy Tools in NIMBY Conflict Management-A Study Based on 25 Cases in China
}

\author{
Yang Liu \\ Soochow University, Suzhou, China \\ Email: 18367819137@163.com
}

How to cite this paper: Liu, Y. (2018) Research on the Influence Factors of the Policy Tools in NIMBY Conflict Management-A Study Based on 25 Cases in China. Open Journal of Social Sciences, 6, 164-174.

https://doi.org/10.4236/jss.2018.69011

Received: August 27, 2018

Accepted: September 9, 2018

Published: September 12, 2018

Copyright $\odot 2018$ by author and Scientific Research Publishing Inc. This work is licensed under the Creative Commons Attribution International License (CC BY 4.0).

http://creativecommons.org/licenses/by/4.0/

\begin{abstract}
NIMBY conflict is a kind of public crisis incident accompanied by the development of society. This problem stems from the NIMBY syndrome of citizens in the process of constructing NIMBY facilities and the essence of this problem is the uneven distribution of interests. In this paper, the policy tools in the governance process are divided into three categories: government regulation, collaborative governance, and economic incentives and compensation. According to the research on about 20 cases of NIMBY conflict in China, this paper proposes four main influence factors of policy tools for the management of NIMBY conflict: political factors, civic political awareness, market factors and NIMBY facilities.
\end{abstract}

\section{Keywords}

NIMBY Conflict, Policy Tools, Influence Factors, Typical Cases

\section{Introduction}

With the continuous development of economy and society in China, the demands for quality of life are changing, and civic awareness is gradually developing. More and more citizens begin to pay much attention to the living environment. There are many events about this conflict in China, such as the PX events (in Xiamen, Dalian, Zhangzhou and Qidong) and the construction of incineration plant (in Beijing, Yuhang District and Panyu District). According to the statistical result in the first half of 2016, the number of this kind of events is up to about 50 [1]. NIMBY conflict has challenged the public management capabilities of the government in China. In recent years, many researchers have published papers about this problem. To date, there are over 2000 papers of studying this 
conflict and they have proposed different types of policy tools in solving this problem.

The study of "NIMBY" can be traced back to the 1970s in the United States. The term "NIMBY (Not In My Back Yard)" was first proposed by O'Hare in 1977 [2]. It means that some public facilities are constructed for the benefit of the majority, but the negative external costs are borne by the local residents. After the 1990s, the NIMBY movements emerged in Asia, and then this conflict became one research topic in China. NIMBY conflict is a kind of conflict of interest caused by the negative external effects of neighboring facilities in the specific social environment [3]. Generally, NIMBY conflict is caused by uneven distribution of interests.

\section{The Policy Tools of NIMBY Conflict Management}

It is not a new topic to construct the management of NIMBY conflict from the perspective of public policy. Based on analyzing the characteristics of the NIMBY conflict in China, domestic scholar Baosheng Chen (2012) [3] proposed a public policy circle to optimize the construction of NIMBY facilities to formulate scientific governance policies and reduce the external influences. Yanling $\mathrm{He}$ (2009) and other scholars (Xiaoyan Zhao, 2014; Zhenwei Huang, 2015) [4] [5] [6] had also proposed the "institutional mitigation" and citizen participation to solve problems. According to the research results about the policy tools, this paper will clarify the basic content of policy tools and then analyze the problems existing in the effectiveness of current policy instruments.

Policy tools are used to solve public problems and achieve governmental administration objectives when managing public affairs. It is a bridge connecting policy objectives and policy effects. With the continuous expansion of relevant research, the choice of policy tools has gradually been taken as an important part of solving social conflicts. Because of the publicity, the diversity of subjects, the intensive influence and the destructive effects, the combination of various policy tools is taken as an important role in solving the NIMBY problems. The purpose of this way is to deal with the conflicts of interests in a reasonable and effective manner, to reduce the resistance of constructing NIMBY facilities and to uphold the public benefit. Even though the policy tools for dealing with NIMBY conflict have been widely used in China, they lack the legitimacy and scientificity in some cases. In this way, it is essential to clarify the types of policy tools in solving the problems of NIMBY conflict.

To date, there are over 2000 papers (CNKI) of studying this conflict and they have proposed different types of policy tools in solving this problem. However, there are relatively few studies on policy tools of NIMBY conflict. Among them, Wei Meng and Fanbin Kong (2014) propose three kinds of policy tools in dealing with NIMBY conflict: institutional policy tool for public participation, incentive tools for environmental feedback and internal regulatory tools for reinforced responsibility [7]. Xin Liang (2014) also proposes two types of tools: 
administrative control of the decision-making mode and negotiation of pluralistic participatory governance [8]. Based on relevant research, this paper put forward three policy tools: government regulation, collaborative governance and economic incentive and compensation.

\section{Types of Policy Tools in the Management of NIMBY Conflict}

Although there are many scholars to classify the policy tools of coping with NIMBY conflict, there is no uniform standard. In this paper, the standard of clarify the policy tools comes out of the research of Zhenming Chen (2013) who divides public policy tools into three categories: market-based tools, business management techniques, and social management tools [9]. Combined with the relevant research literature or practice, I divide the policy tools into three kinds:

\subsection{Government Regulation}

This kind of policy tools uses the regulation in public sectors as the main mean to solve NIMBY problems, including the mandatory provisions of relevant laws and regulations on the construction standards of NIMBY facilities as well as the government reform of ensuring political democracy and social stability. These tools can improve the NIMBY syndrome and they can be available at the first period of dealing with NIMBY conflict. Chinese society, however, is still in the transformation period, so the traditional policy tools keep some violent ways in solving problems. For example, in dealing with the Qidong event, the government invoked the armed police to regulate the citizens' evasive movement violently and the suppression is the main cause of intensify contradictions between the public and the government. Therefore, this kind of policy tools is often accompanied with other policy tools in practice.

\subsection{Collaborative Governance}

While the government plays a leading role in solving various social issues, NIMBY conflict in China has special heterogeneity. NIMBY conflict demonstrates the development of civil society and environmental awareness and it is restricted by traditional regulatory thinking as well. As a result, the traditional tools can not meet requirements of handling NIMBY conflict. Based on this context, the model of collaborative governance is proposed and then it develops a new kind of policy tool in dealing with NIMBY conflict. This kind of policy tools emphasizes multiple coordinated governance and it claims that government, society and market entities can clarify the right and responsibilities clearly. In this way, multiagent can cooperate in managing social affairs. Although the government plays a leading role, it needs to delegate powers to lower levels, such as communities and markets. In fact, collaborative governance is conducive to breaking the mould of omnipotent government in traditional ideas of social management and to promoting the progress of civil society (or civil society organizations). In this kind of policy tools, the citizen participation system is taken 
as the core of dealing with NIMBY conflict. The best way of realizing civic participation, however, is the development of the third sectors, which can provide a wider channel for citizens to express their needs. The legitimate rights and interests of citizens are also expressed in other channels such as agency hearings and community autonomy. While using this kind of policy tools, the most crucial work in collaborative governance is the construction of exchanging public information. With this basis, the collaborative governance can be used in an effective way.

\subsection{Economic Incentive and Compensation}

Economic incentives have been widely using in the practice of solving various problems in NIMBY conflict. Although they do not play a decisive role in resolving conflicts, they are essential. Economic incentive and compensation can be divided into two types: direct economic compensation and brief economic compensation. The direct economic compensation compensates citizens' interests by means of material and monetary subsidies. At the same time, the government also mitigates or eliminates contradictions through the indirect economic compensation, for example tax reduction and exemption. Generally, economic tools need the market's function which can establish a competitive mechanism for reducing the construction costs of NIMBY facilities and mitigate the negative external risks of NIMBY facilities by improving the technical requirements. In this kind of policy tools, the government, the relevant enterprises and citizens can achieve a win-win situation by means of contracts or agreements.

Clarifying the different types of policy tools in handling NIMBY conflict is an important condition for finding the main problems in solving NIMBY issues. But this does not mean that the NIMBY conflict can be solved. In order to find the proper policy tools for various NIMBY events, the influence factors of the effectiveness of policy tools for managing NIMBY conflict should be further explored.

\section{Typical Cases in China}

According to the types of policy tools in the management of NIMBY conflict, this paper will illustrate the main factors in different cases and then conclude the main influence factors in the management of NIMBY conflict.

Table 1 shows the 20 typical cases in the last 10 years in China and they have been analyzed on the basis of three types of policy tools ( $1=$ Government regulation; 2 = Collaborative governance; 3 = Economic incentive and compensation). It is clear that the policy tools of government regulation and collaborative governance are frequent used by governments. Furthermore, over 10 cases have adopted the combination of different types of policy tools and the citizens' attitudes have showed the improvement in some cases, for instance, the WWTPs (Wastewater Treatment Plants) in Nantong. 
Table 1. 20 cases in China (2008-2018).

\begin{tabular}{|c|c|c|c|c|c|}
\hline Cases & Types & Political fundamentals & Citizens & Market & NIMBY facilities \\
\hline $\begin{array}{l}\text { Nuclear power station } \\
\text { in Xinyang (2008) }\end{array}$ & $1+2$ & Modern system & Rejection & $\mathrm{N}$ & Location \\
\hline $\begin{array}{c}\text { Maglev vehicle } \\
\text { in Shanghai (2008) }\end{array}$ & 2 & Modern system & Rejection & $\mathrm{N}$ & $\begin{array}{c}\text { Location; } \mathrm{N} \\
\text { egative externalities }\end{array}$ \\
\hline $\begin{array}{l}\text { Incineration plant } \\
\text { in Fanyu (2009) }\end{array}$ & $1+2$ & Traditional to modern system & $\begin{array}{l}\text { Rejection to } \\
\text { acceptance }\end{array}$ & $\mathrm{N}$ & $\begin{array}{c}\text { Location; } \\
\text { Negative externalities }\end{array}$ \\
\hline $\begin{array}{l}\text { Incineration plant } \\
\text { in Wujiang (2009) }\end{array}$ & 1 & Traditional system & Rejection & $\mathrm{N}$ & Negative externalities \\
\hline $\begin{array}{l}\text { Incineration plant } \\
\text { in Beijing (2009) }\end{array}$ & $1+2$ & Traditional to modern system & $\begin{array}{l}\text { Rejection to } \\
\text { acceptance }\end{array}$ & $\mathrm{N}$ & Location; Effects \\
\hline $\begin{array}{c}\text { Graveyard } \\
\text { in Beijing (2009) }\end{array}$ & 2 & Modern system & Rejection & $\mathrm{N}$ & $\begin{array}{c}\text { Location; } \\
\text { Negative externalities }\end{array}$ \\
\hline $\begin{array}{c}\text { Methadone service } \\
\text { station in Macao (2010) }\end{array}$ & $1+2$ & Traditional to modern system & Rejection & $\mathrm{N}$ & Location \\
\hline PX event in Dalian (2011) & 1 & Traditional system & Rejection & $\mathrm{N}$ & Location; Negative effects \\
\hline $\begin{array}{l}\text { Jing-Shen high-speed } \\
\text { rail event (2012) }\end{array}$ & 2 & Modern system & $\begin{array}{l}\text { Rejection to } \\
\text { acceptance }\end{array}$ & Technology & $\begin{array}{c}\text { Location; } \\
\text { Negative externalities }\end{array}$ \\
\hline $\begin{array}{c}\text { WWTPs } \\
\text { in Nantong (2010) }\end{array}$ & $2+3$ & Modern system & $\begin{array}{l}\text { Rejection to } \\
\text { acceptance }\end{array}$ & Benefits & $\begin{array}{c}\text { Location; } \\
\text { Negative externalities }\end{array}$ \\
\hline $\begin{array}{c}\text { Funeral parlor } \\
\text { in Qingdao (2012) }\end{array}$ & $1+2$ & Modern system; Public value & Rejection & $\mathrm{N}$ & Location \\
\hline $\begin{array}{l}\text { Molybdenum project } \\
\text { in Shifang }(2012)\end{array}$ & 1 & Traditional to modern system & Rejection & $\mathrm{N}$ & $\begin{array}{c}\text { Location; } \\
\text { Negative externalities }\end{array}$ \\
\hline $\begin{array}{l}\text { Kitchen waste station } \\
\text { in Beijing (2011) }\end{array}$ & $1+2$ & Public trust; Traditional system & Rejection & social responsibility & $\begin{array}{c}\text { Location; } \\
\text { Negative externalities }\end{array}$ \\
\hline $\begin{array}{l}\text { "sea drainage project" } \\
\text { in Qidong (2012) }\end{array}$ & $1+2$ & Traditional to modern system & Rejection & social responsibility & Prejudice public interests \\
\hline $\begin{array}{c}\text { PX event } \\
\text { in Maoming (2014) }\end{array}$ & 1 & Traditional to modern system & Rejection & $\mathrm{N}$ & $\begin{array}{c}\text { Location; } \\
\text { Negative externalities }\end{array}$ \\
\hline $\begin{array}{l}\text { Incineration plant } \\
\text { in Hangzhou (2014) }\end{array}$ & $1+2+3$ & Public value; Modern system & $\begin{array}{l}\text { Rejection to } \\
\text { acceptance }\end{array}$ & Evaluation & Negative externalities \\
\hline $\begin{array}{c}\text { Funeral parlor } \\
\text { in Huazhou (2014) }\end{array}$ & 1 & Traditional system & Rejection & $\mathrm{N}$ & Negative externalities \\
\hline $\begin{array}{c}\text { PX Project } \\
\text { in Zhangzhou (2015) }\end{array}$ & 1 & Government Failure & $\begin{array}{l}\text { Acceptance to re- } \\
\text { jection }\end{array}$ & $\mathrm{N}$ & Prejudice public interests \\
\hline $\begin{array}{l}\text { Incineration plant } \\
\text { in Xiantao (2016) }\end{array}$ & $1+2$ & Modern system & Rejection & $\mathrm{N}$ & $\begin{array}{c}\text { Location; } \\
\text { Negative externalities }\end{array}$ \\
\hline $\begin{array}{c}\text { Substation } \\
\text { in Shenzhen (2017) }\end{array}$ & $1+2$ & Public value; Modern system & Rejection & $\mathrm{N}$ & $\begin{array}{c}\text { Location; } \\
\text { Negative externalities }\end{array}$ \\
\hline
\end{tabular}

While analyzing the situation of various cases, it all based on four criteria: the government's political fundamentals (traditional management system, modern democratic system, public value orientation and so on), citizens' attitudes, market factors and internal issues in NIMBY facilities. These criteria are obtained among relevant literature review and lots of cases and they can reveal the results 
in various cases in which they have used different types of policy tools. In this table, the political fundamentals vary from case to case but the majority of 20 cases have modern democratic system. The citizens' attitude to NIMBY facilities can show the final results of all cases. When citizens keep the attitude of rejection, it means that the policy tools in the NIMBY conflict management do not work. And when they change the attitude from rejection to acceptance, it means that the policy tools in these cases have played a role.

\section{Influence Factors of Policy Tools in the Management of NIMBY Conflict}

Judging from the analysis of 20 cases, many factors of policy tools in the process of handling conflicts are related to the effect of policy implementation directly. According to the relevant literature and the cases analysis, this paper will illustrate four main factors:

\subsection{Political Fundamentals}

NIMBY conflict is a kind of public events, so the certain political conditions should be taken as the priority. Therefore, the democratic political factors are the primary factors in affecting the effectiveness of policy tools. Starting from the characteristics of NIMBY events in these typical cases, the factors of political fundamentals can be analyzed from the following points:

Firstly, the construction of modern democratic system is an important foundation for guaranteeing the reasonability and the legitimacy of the government. It is not only conducive to coordinating conflicts between various stakeholders, but also the necessary conditions for promoting citizen participation and collaborative governance. In many cases, the political democracy development in China has absorbed the excellent content of the Western democratic system, such as the construction of democracy and the rule of law. Even though the results in some cases are not obvious, they have been proven invalid in the cases of Incineration plant in Wujiang and PX event in Dalian. However, China has a long history of feudal rule. The traditional management methods and management ideologies are contradictory to modern democratic systems and civic thoughts. Because of the limitation of its management ability, the government still has the problems on adjusting this contradiction effectively. On the basis of this context, there are 6 cases which have the process from traditional management to modern system and 2 cases (Incineration plant in Beijing and Fanyu) which have changed the attitude of citizens in the end. So the policy tools need the construction of modern democratic system to guarantee social fairness. In this way, the lawful rights and interests of the citizens can be protected and NIMBY syndrome of citizens can be changed.

Secondly, the government failure is a factor of affecting the effectiveness of policy tools. According to the Public Choice Theory, both government officials and citizens act as "rational people" and it means that they all have a self-interest 
tendency in their choices. In this theory, officials will use public power to seek for private benefits, and some NIMBY facilities can be used to obtain private interests for officials. This kind of behavior of officials is known as "rent-seeking activity". There are some cases which show the officials make use of public power for private. In some cases such as the PX Project in Zhangzhou, government pay more attention to securing the self-interest rather than guaranteeing public interest. Therefore, the public distrust in government and the NIMBY syndrome will become the major resistance to resolve NIMBY conflict. In this context, citizens would tend to believe that the NIMBY facilities are built for private benefits or free riding of the majority and then the relevant policies are not able to function in dealing with NIMBY problems. Seen in this light, government failure can have a huge impact on the performance of policy tools.

Thirdly, the factor of political value orientation plays an important role in the process of governance as well. In the 20 cases, almost all governments' value is oriented to public interests while not in line with public requirements. When the government takes the public interest as its value orientation, for example in the case of incineration plant in Hangzhou, the government which put the public value in practice at the beginning of the project had got public acceptance. If the government regards the refusal movement of citizens as an act of self-interest and ignorance, it often chooses a compulsory policy tool which has proven ineffective in dealing with conflicts (Funeral parlor in Huazhou). Therefore, the government must change its value orientation toward the NIMBY facilities and the public.

\subsection{Citizen Political Psychology}

Political psychology is a kind of citizens' psychological reflection of social and political phenomena and political relations in social practice and it is intuitive and spontaneous (Puzhen Wang, 2014) [10]. It means that the government actions and decisions will have an impact on citizen political psychology in the process of social administration, and this psychology will feed back to government policy. In this circle, the value judgment of citizens on government policies has impact on the public support or opposition to policy tools.

The formation of citizens' political consciousness is a process step by step. At the beginning of the formation, the residents have a certain understanding of NIMBY facilities. These cognitions are vague and with the development of the NIMBY conflict, residents' worries about the risk of NIMBY facilities and the consideration of their interests will enable citizens to make choices in the behavior. Because political psychology acts as an irrational reaction in practice, abnormal and fierce protests occur in some NIMBY events. This situation will have hindered or destructive effects on government-related policy implementation. Therefore, whether the policy tools could change citizens' political psychology effectively is an important indicator for measuring the effectiveness of policy instruments. 
Citizens have contradictory attitudes toward the management of Chinese-style NIMBY conflict and they are affected by the traditional predominantly patriarchal culture. When citizens encounter problems, they have a path dependence on government. As a result, people tend to rely on governments to solve problems while governments are not able to resolve the conflict effectively. Under the influence of the actual implementation effect of the government decisions, governments' reliability has become lower. Therefore, when citizens feel unfair in the process of distributing benefits of NIMBY facilities, they often express the negative political attitudes to the policy tools of resolving NIMBY conflict and then citizens will take actions to resist implementing government policy. In fact, this is the reason for why citizens keep the attitude of rejection at first in almost all cases.

\subsection{Market Factors}

As the basic mean to adjust economic interests, the market is built on the perfect market economic system. In the process of solving NIMBY problems, market-oriented tools such as economic compensation and enterprise bidding, play an important role. In this case, market factors include economic factors and enterprises factors:

Economic factors in many cases have been emphasized but the policy tools often implemented by local governments or the third sector. According to the game theory, the essence of NIMBY conflict is the interest game among different subjects or interest groups. Because the interests of NIMBY facilities are unevenly distributed and the government, enterprises and residents have different standards in calculating costs and benefits, their cognition and behavior are affected by calculating results, and then contradiction become acute. Accordingly, the calculation of costs and benefits of various bodies will affect the function of policy tools.

Enterprises are the main players in the market and the mainstay of building NIMBY facilities. Therefore, they also have an important impact on the performance of policy tools. Due to the aim of profit making, the construction enterprises will put their own benefits first. With growing awareness of public responsibility, many enterprises have to shoulder more technical and social responsibilities to reduce the risk of building public facilities. In other words, enterprises need to consider their public image which is related to the public attitudes toward the NIMBY projects. For instance, the construction enterprise in the PX Project in Zhangzhou did not take its responsibility in security and then it caused an explosion which led to the damage to public interests. In such cases, enterprises' role in dealing with NIMBY conflict can affect the result of policy tools.

\subsection{NIMBY Facilities}

There are two main points (Location and the facilities' negative externalities) in 
20 cases. The public-benefitting NIMBY facilities such as nuclear plants and chemical engineering, are based on public interests and they have uncertain risks which are not able to be eliminated completely even if the technology and management of these facilities are continuously updated and optimized. The main stakeholders of these projects are the surrounding residents. In this situation, the key to the conflict is the distance between citizens and NIMBY facilities. Therefore, the effectiveness of policy tools in management of NIMBY conflict is positively related to the location and latent risks of public-benefitting NIMBY facilities.

There are some NIMBY facilities such as funeral homes and garbage incineration plants, which have psychological or physiological negative impacts on residents. Fundamentally, such facilities' acceptability in the public is generally low. Therefore, the effectiveness of relevant policy tools will also decrease.

\section{Countermeasures Based on Influence Factors}

According to the analysis of 20 cases and the main influence factors, there are three main methods for resolving NIMBY conflict.

\subsection{System Construction}

In the analysis of the influencing factors, the construction of modern democratic institutions plays an essential role in functioning the policy tools. Because the center of democratic system construction is the construction of the rule of law, the first step is to improve the construction of relevant systems to promote the management of democracy and the rule of law:

The first method is to improve the citizen participation system which will help reduce "resistance" of the public. The second is to establish an information disclosure and exchange system. This will provide a communication system with which the relevant stakeholders can solve the problems of information asymmetry. The third method is to improve the economic incentive mechanism. Economic incentives can be divided into direct compensation and indirect compensation. The former way generally refers to monetary subsidies, reductions and exemptions of related taxes and fees and so on. The indirect compensation contains the methods of improving living standard of and environment and citizens. The forth is to strengthen the construction of crisis management system and to build the model of multi-agent collaborative management which are the effective ways to resolve NIMBY conflict. By establishing the early warning system and supervisory system, the government will be able to form a response mechanism for NIMBY events and then it can respond to various problems effectively in NIMBY conflict.

\subsection{Psychological Construction}

Based on the influence factors of the citizens' political psychology, the most important way in psychological construction is the building of trust between citizens 
and the government. In this process, the government needs to guide the transformation of citizens' political psychology so that it can promote the development of the rational participation of citizens in the supervision and management of social issues. The Second way is the construction of fairness. It means that the government needs to build its public trust and then reduces the sense of imbalance of citizens in the process of benefit distribution.

\subsection{Innovation Construction}

There are some good management approaches in the process of foreign government governance and these experiences can be used for improving the NIMBY problems in China. For example, the Japanese model (Multi-agent collaborative governance model) [11] provides the combination of different policy tools to solve the problems in NIMBY conflict. It combines citizen participation, social autonomy and market tools in a sustainable way so that it can be used to solve the similar social issues as well. When learning from foreign management experience, it is necessary to combine the characteristics of Chinese-style NIMBY conflict to promote the fittest policy tools in line with the development of urbanization of China. This means that our society needs to build an innovative method which is the suitable approach to resolve the Chinese-style NIMBY conflict.

In addition, technological innovation also needs to be concerned. By increasing the investment in technical research and development, it can reduce the latent risks and the costs of NIMBY facilities.

\section{Conclusion}

"China Dream" has become a well-known topic in China. In the process of urbanization construction, the quality of citizens is becoming more and more important. There are many problems in the Chinese-style NIMBY conflict, such as irrational thinking of citizens. On the whole, the management of NIMBY conflict still needs continuous improvement. Although this paper discusses the influence factors of policy tools for NIMBY conflict's governance, the content of this essay is superficial research. In the future, we could make a further study of the effectiveness of policy tools by empirical research.

\section{Conflicts of Interest}

The authors declare no conflicts of interest regarding the publication of this paper.

\section{References}

[1] Zhang, M.J. and Liu, X.L. (2017) Analysis Report of Social Mass Incidents in China in 2016. Advances in China Public Security, 1, 1-18.

[2] He, Y.L. (2006) The Conflict Caused By "Not InMy Back Yard” and Its Solution: Analysis Based on Ubran Collection Protest. Public Management Research, 12, 93-103.

[3] Chen, B.S. (2012) NIMBY Conflict and Its Governance in the Process of Public Policy. Journal of Xuehai, 5, 110-115. 
[4] He, Y.L. (2009) "Chinese-Style” NIMBY Conflict: An Event-Based Analysis. Open Times, 12, 102-114.

[5] Zhao, X.Y. (2014) Foreign Literature Review on NIMBY Conflict. Journal of Hubei University of Economics (Humanities and Social Sciences), 11, 26-27.

[6] Huang, Z.W. (2015) “Semi-Public Decision-Making Model”-Governments' Strategy on Responding to NIMBY Conflict. Journal of Hubei University (Social Sciences), 29, 132-136.

[7] Meng, W. and Kong, F.B. (2014) Cause Analysis and Selection of Governance Instruments for NIMBY Issues-Perspective Based on the Structural Distribution of Policy Interests. Journal of Jiangsu Administration Institute, 2, 119-124.

[8] Liang, X. (2014) Study on Governance Mode Transition of NIMBY. MD. Nanjing University, 5.12 .

[9] Chen, Z.M. (2013) Public Policy. China Renmin University Press, Beijing, 149-150.

[10] Wang, P.X. (2014) Political Science Foundation. Peking University Press, Beijing, 243-248.

[11] Zhou, Y.Y. and Yu, H.S. (2015) On the Economic Approaches for Regulating NIMBY Conflicts and Externalities. Zhejiang Social Sciences, 2, 54-59. 